\title{
The effect of COVID-19 on schoolteachers' emotional reactions and mental health: longitudinal results from the CLASS study
}

\author{
Kirsten Nabe-Nielsen ${ }^{1}$ (i) $\cdot$ Karl Bang Christensen ${ }^{2}$ (i) $\cdot$ Nina Vibe Fuglsang ${ }^{3} \cdot$ Inge Larsen $^{3} \cdot$ Charlotte Juul Nilsson $^{1}$ (D)
}

Received: 4 June 2021 / Accepted: 2 September 2021 / Published online: 18 October 2021

(c) The Author(s), under exclusive licence to Springer-Verlag GmbH Germany, part of Springer Nature 2021

\begin{abstract}
Purpose We investigated schoolteachers' emotional reactions to COVID-19 and mental health during three phases of the COVID-19 pandemic. We further analyzed if teachers, who belonged to a COVID-19 risk group, had more emotional reactions and poorer mental health than "non-risk" groups.

Methods We collected questionnaire data in May, June, and November-December 2020 and used data from 2665 teachers at public schools (871 individuals participated in all three surveys). Participants reported their fear of infection, fear of transmission of infection to their home or pupils, perceived burnout and stress, and worries about their ability to manage the working conditions. We included information about COVID-19 risk group status, gender, age, organization of teaching (physical presence or remote teaching), and the pupils' grade. We estimated prevalence ratios and took repeated measures into account.

Results Emotional reactions and poor mental health increased significantly with 27-84\% from May to November-December 2020. Teachers, who were particularly vulnerable to the adverse consequences of COVID-19, had the highest prevalence of fear of infection and poor mental health.

Conclusion Teachers play a crucial role in a society's response to a pandemic. Yet, the dual role of teaching and virus control along with concerns regarding the health consequences of an infection may contribute to the observed increase in emotional reactions to COVID-19 and poor mental health.
\end{abstract}

Keywords COVID-19 $\cdot$ Mental health $\cdot$ Occupational health $\cdot$ School teachers $\cdot$ Longitudinal studies

Kirsten Nabe-Nielsen

nabe@sund.ku.dk

Karl Bang Christensen

kach@sund.ku.dk

Nina Vibe Fuglsang

nvf@dlf.org

Inge Larsen

inl@dlf.org

Charlotte Juul Nilsson

cjni@sund.ku.dk

1 Section of Social Medicine, Department of Public Health, University of Copenhagen, Øster Farimagsgade 5, 1014 Copenhagen, Denmark

2 Section of Biostatistics, Department of Public Health, University of Copenhagen, Øster Farimagsgade 5, 1014 Copenhagen, Denmark

3 Danish Unions of Teachers, Vandkunsten 12, 1467 Copenhagen, Denmark

\section{Introduction}

The COVID-19 pandemic has profound implications for the working environment among frontline employees (Burdorf et al. 2020). Frontline employees encompass job groups working with customers, clients, patients, pupils, etc. and they often maintain essential functions that cannot be maintained from home (The Lancet Editorial 2020). Not surprisingly, the working environment and mental health particularly among healthcare professionals have received attention during the pandemic (Chew et al. 2020; Huang and Zhao 2020; Song et al. 2020; Sun et al. 2020; Vindegaard and Benros 2020). Yet, when it comes to the control of a virus outbreak, also institutions outside of the hospital sector play a major role, for example, public schools.

Globally, school closures are a frequently used approach to control virus outbreaks (Viner et al. 2020). Yet, according to UNESCO, the duration of school closures varies considerably between different countries and regions (UNESCO 
2021). Thus, when schools are open during pandemics, schoolteachers are expected to hinder spread of infection while carrying out their core tasks ( $\mathrm{Li}$ et al. 2020a). We hypothesized that this double role, combined with the risk of infection due to multiple social contacts, affects teachers' emotional reactions to COVID-19 and mental health, and these consequences may be more pronounced in risk groups that are particularly vulnerable to severe illness in the case of an infection with SARS-Cov-2 (Preskorn 2020).

Knowledge about these effects of the pandemic is not only of importance for teachers, but also for pupils, parents and the school leaders, who are directly or indirectly affected by teachers' wellbeing (Naghieh et al. 2015). Additionally, the teachers' ability to navigate their double role during pandemics, i.e., hindering spread of infection while teaching, is of interest to society as a whole due to the spillover effect of virus outbreaks at schools on the infection rates in the society, pressure on the health care sector, and the economy.

A range of cross-sectional studies conducted during the 2020 lock-down describe teachers' mental health problems in the context of COVID-19 (Aperribai et al. 2020; Li et al. 2020b; Lizana and Vega-Fernadez 2021; Sokal et al. 2020b; Stachteas and Stachteas 2020; Zhou and Yao 2020), while one Spanish cross-sectional study reported the level of poor mental health among teachers in relation to reopening of schools (Ozamiz-Etxebarria et al. 2020). Interestingly, one UK report described fluctuations in anxiety among teachers from October 2019 to September 2020 and highlighted peaks in anxiety in the week before initial lockdown and again in the week that a school re-opening was announced (Allen et al. 2020). In Chilean teachers, quality of life decreased during the pandemic compared with pre-pandemic measures (Lizana et al. 2021), and a study among Canadian teachers reported increased exhaustion and cynicism during the first three months of the pandemic (Sokal et al. 2020a). Thus, teachers' mental health may be challenged during the pandemic, but due to the cross-sectional nature of the majority of previous studies, there is still a lack of knowledge about the consequences of being in the frontline and the resulting changes in teachers' mental health during different phases of the COVID-19 pandemic.

The aim of the present study was, therefore, to investigate changes in schoolteachers' emotional reactions to COVID19 and mental health during three phases of the COVID-19 pandemic in Denmark: A semi-initial phase with a partial school closure and declining infection rates (May 2020), an intermediate phase with open schools and low infection rates (June 2020), and in the beginning of a second wave with high and increasing infection rates and open schools (November-December 2020). We further analyzed if the effect of the pandemic on emotional reactions and mental health was stronger among teachers in a COVID-19 risk group.

\section{Methods}

\section{Data collection}

We used data from baseline, 1st and 2nd follow-up of the CLASS study. CLASS is a national research project on the effects of COVID-19 on teachers' working environment, sense of community and perceived risk of infection in Denmark. Data were collected via an online questionnaire between 6 and 17 May 2020, 16 and 26 June 2020, and 25 November to 9 December 2020. The questionnaires were distributed by email including 1-2 reminders. The Danish Union of Teachers (DLF), which organizes teachers employed in public schools in Denmark, managed the data collection. In the invitation to the survey, it was highlighted that participation was voluntary, that responses were confidential, and that individuals or workplaces could not be identified, when results were published. A link to further information was provided to fulfill the requirements of the Data Protection Regulation. In Denmark, questionnaire surveys do not need ethical approval.

\section{Context}

Figure 1 illustrates the context of the data collection in relation to different phases of the COVID-19 pandemic. In Denmark, the first case of COVID-19 was identified 26 February 2020, and 11 March 2020 a total lock-down of all public workplaces apart from critical functions was announced. During the lock-down, public teachers implemented remote emergency teaching. By 17 April 2020, public schools were re-opened for the youngest pupils [0th (approx. 6-7 years old) to 5th grade (approx. 11-12 years old)]. During the baseline data collection, a re-opening was announced starting from 18 May for older pupils [6th grade (approx. 12-13 years old) to 10th grade (approx. 16-17 years old)]. During the summer and fall, all public schools were open apart from temporary local or regional school closures in the case of local outbreaks. From 9 December 2020, i.e., the last day of the data collection for the 2nd follow-up, public schools were closed again, now including 5th to 10th grade.

\section{Study population}

DLF has approximately 50,000 members. The initial study population consisted of a random sample of the members of DLF, who were employed as teachers in public schools. In total, 10,000 members were contacted. Participants were eligible for inclusion if they were currently engaged in teaching either remotely or physically (or both) at the 


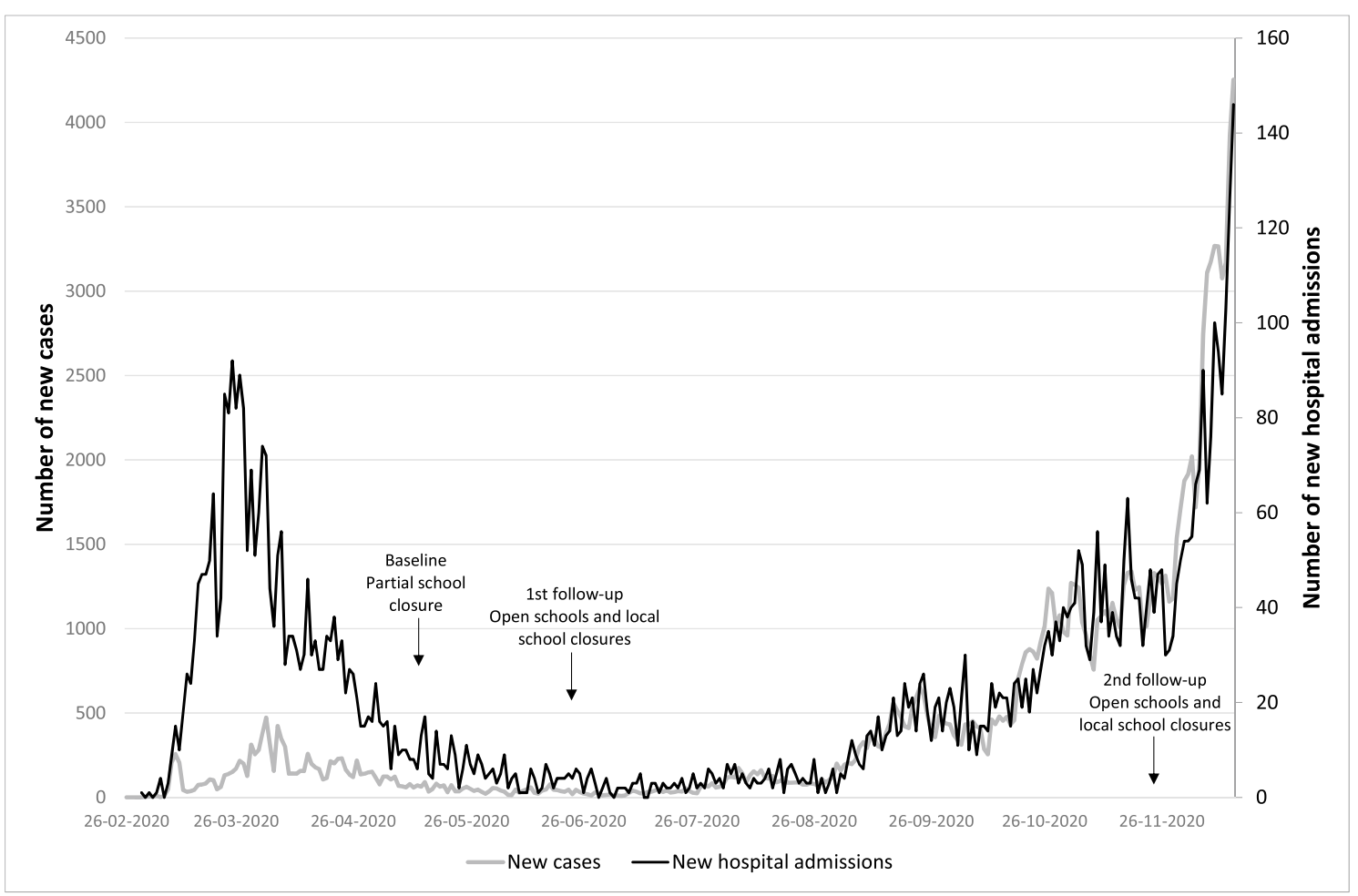

Fig. 1 Overview of the context of the data collection. The figures are based on publicly available data from "Statens Serum Institut" (Statens Serum Institut 2021) Note: The number of newly infected in the spring and in the fall is incomparable due to difference in the test- ing strategy. The mean number of daily hospital admissions with COVID-19 during the days of data collection was 9 (May 2020), 4 (June 2020), and 54 (November-December 2020) schools at the time of the survey. Only teachers working at least partly outside of the specialized area (comprising children with special needs) were included. Figure 2 shows a flow diagram of the respondents of each survey. The response rates were $30 \%$ (baseline), $54 \%$ (1st follow-up), and $59 \%$ (2nd follow-up). Response rates did not differ substantially between men and women, but the response rate was lowest in Region North Jutland and among those, who were below 40 years old. Among CLASS participants, particularly the younger age group (20-39 years) was underrepresented, while the older age groups (50-59 years and $\geq 60$ years) were overrepresented, as compared with DLF members in general. Among those who fulfilled the inclusion criteria and participated in at least one survey, we excluded individuals missing on age and gender leaving us with an analytical sample of $n=2665$ at baseline, $n=1239$ at 1 st follow-up, and $n=1329$ at 2 nd follow-up. In total, 871 individuals were eligible for inclusion, had non-missing data on age and gender, and participated in all three surveys. The distribution of sociodemographic factors, current teaching, and risk group status in the total sample and among those who participated in all three surveys is displayed in Table 1.

\section{Variables}

\section{Sociodemographic factors}

Information about gender, age and region was obtained from DLF's members' register. Cohabitation was assessed with the question "Do you live together with...?" (Response options: My parents, Partner, Other adults, Children in 5th grade or younger, Children in 6th grade or older, I live alone), and participants were categorized in four groups (see Table 1).

\section{Current teaching}

We obtained information about the organization of the participants' teaching [How is your teaching currently organized? Response options: Teaching at the school, Remote teaching, I do not teach currently (The latter group was excluded from the survey)], and the pupils' grade (What grades are you currently teaching? 0th grade...10th grade). Hybrid teaching was not available as a response category. 


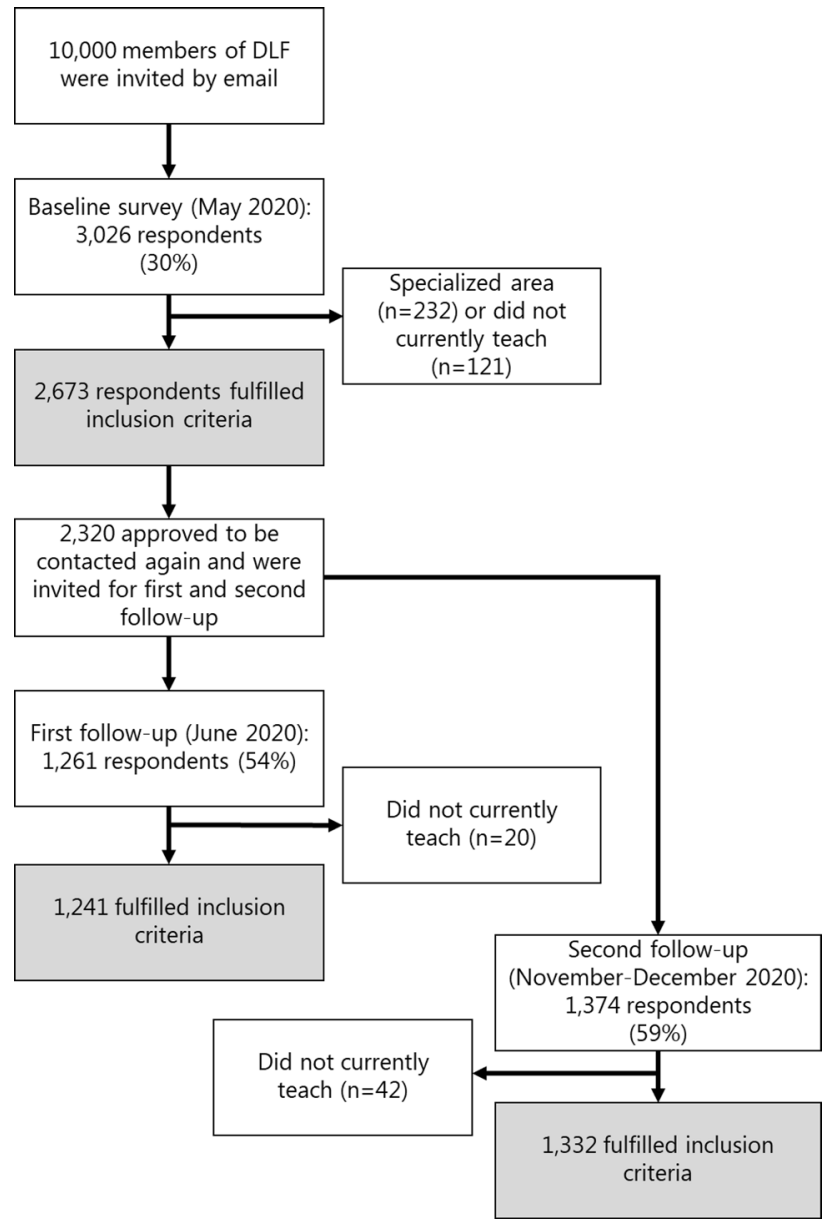

Fig. 2 Flow diagram of the participation in each survey (baseline, first and second follow-up). The analytical samples were as follows: Baseline $n=2665$, first follow-up $n=1239$, second follow-up $n=1329$, and available data from all three surveys $n=871$

\section{Emotional reactions}

Participants were asked: If you think about your current situation, do you agree or disagree with the following statements...? (a) I fear being infected with COVID-19 during my work; (b) I fear to transmit infection from my workplace to my home; (c) I fear transmitting infections to my pupils during work [Response options: (1) Highly agree, (2) Agree, (3) Neither agree nor disagree, (4) Disagree, (5) Highly disagree]. The variables were dichotomized and participants who agreed or highly agreed were considered as having an emotional reaction. Only participants who had been physically present at the school in the preceding period (either teaching or at meetings, picking up material, printing, etc.) were responding to these questions. At baseline, the Cronbach's Alpha for the three original items was 0.86 .
Table 1 Description of the baseline sample eligible for inclusion (total sample) and the subsample who participated in all three surveys (May, June and Nov-Dec 2020)

\begin{tabular}{|c|c|c|c|c|}
\hline & \multicolumn{2}{|c|}{$\begin{array}{l}\text { Total sample } \\
N=2665\end{array}$} & \multicolumn{2}{|c|}{$\begin{array}{l}\text { Subsample } \\
N=871\end{array}$} \\
\hline & $\%$ & $n$ & $\%$ & $n$ \\
\hline \multicolumn{5}{|l|}{ Gender } \\
\hline Female & 76 & 2032 & 78 & 675 \\
\hline Male & 24 & 633 & 23 & 196 \\
\hline \multicolumn{5}{|l|}{ Age } \\
\hline$<40$ years & 20 & 522 & 14 & 121 \\
\hline 40-49 years & 33 & 875 & 33 & 289 \\
\hline $50-59$ years & 33 & 875 & 38 & 333 \\
\hline 60 years or older & 15 & 393 & 15 & 128 \\
\hline \multicolumn{5}{|l|}{ Region } \\
\hline Capital & 26 & 701 & 24 & 211 \\
\hline Zealand & 15 & 402 & 16 & 141 \\
\hline Southern Denmark & 11 & 281 & 10 & 84 \\
\hline Mid Jutland & 25 & 673 & 27 & 231 \\
\hline North Jutland & 23 & 608 & 23 & 204 \\
\hline \multicolumn{5}{|l|}{ Cohabitation } \\
\hline Live alone & 11 & 300 & 11 & 100 \\
\hline Live solely with children & 10 & 258 & 7 & 64 \\
\hline Live solely with other adults & 37 & 983 & 38 & 335 \\
\hline Live with children and adults & 42 & 1124 & 43 & 372 \\
\hline \multicolumn{5}{|l|}{ Grades $^{\mathrm{a}}$} \\
\hline 0. -3 . grade & 39 & 1035 & 40 & 346 \\
\hline 4. -6 . grade & 44 & 1174 & 45 & 388 \\
\hline 7. -10. grade & 39 & 1034 & 38 & 334 \\
\hline \multicolumn{5}{|l|}{ Type of teaching } \\
\hline At the school & 50 & 1337 & 51 & 445 \\
\hline Remote teaching from home & 33 & 880 & 30 & 265 \\
\hline Both & 17 & 448 & 19 & 161 \\
\hline \multicolumn{5}{|l|}{$\begin{array}{l}\text { Belongs to a risk group in relation to } \\
\text { COVID- } 19^{\mathrm{b}}\end{array}$} \\
\hline No & 83 & 1025 & 83 & 726 \\
\hline Yes & 14 & 171 & 13 & 114 \\
\hline Do not know/do not wish to report & 4 & 43 & 4 & 31 \\
\hline Missing data & - & 1434 & - & 0 \\
\hline
\end{tabular}

${ }^{\mathrm{a} P a r t i c i p a n t s ~ c o u l d ~ t e a c h ~ m o r e ~ t h a n ~ o n e ~ g r a d e . ~}{ }^{\mathrm{b}}$ Data extracted from June survey. Participants who reported "Do not know/do not wish to report" were excluded from the analyses of this variable

\section{Mental health}

Participants were asked the following questions: (d) Have you felt stressed during the past 2 weeks? [Response options: (1) All the time, (2) Often, (3) Sometimes, (4) Seldom, (5) Never]; (e) Do you feel burned out because of your work?; (f) Does it worry you whether you can manage working under the current conditions for a longer period of time? (Response options for item e and f: To a very high degree, 
To a high degree, To some degree, To a small degree, Not at all). The variables were dichotomized, and participants in the first two categories were considered as having poor mental health. At baseline, the Cronbach's Alpha for the three original items was 0.87 .

\section{Risk group status}

In June 2020, participants were asked if they belonged to a COVID-19 risk group (Response options: Yes, No, Do not know, Do not want to answer). Participants were presented with the Danish Health Authorities' definition of risk groups, which are individuals who are above the age of 80 years or institutionalized, adults who are obese or have a chronic disease, children with a chronic disease making them vulnerable to infections, and pregnant women. As we did not have information about risk-group status from the baseline survey (May 2020), analyses of the effect of being in a risk group on emotional reactions and mental health were only conducted in the subsample with information from all three surveys. Also, those who did not know or who did not want to respond to this question were excluded from these analyses $(n=43)$.

\section{Statistical analyses}

First, we analyzed the distribution of sociodemographic variables and other covariates in the two analytical samples, i.e., the "total sample" (i.e., all respondents at each time point) and the "subsample" (i.e., only respondents who participated at all time points) (Table 1).

Second, we described the level of emotional reactions and mental health across the three phases of the pandemic in both samples (Fig. 3), and analyzed differences across time (May, June, November-December) with adjustment for gender, age, region, cohabitation, organization of teaching, and the pupils' grades in the total sample (Table 2).

Third, in the subsample, we investigated changes in emotional reactions and mental health among teachers, who belonged to a COVID-19 risk group compared with teachers, who did not belong to a risk group, with formal test of multiplicative interaction by adding a "Time $\times$ Risk group" interaction term (Table 3).

We used repeated measurements logistic regression as implemented in the the $\mathrm{glm}$-procedure in STATA version 15.1. Prevalence ratios (PR) with $95 \%$ confidence intervals (CI) were used as effect estimates. In these analyses, the clustered nature of the data was taken into account using the STATA command for robust clusters.

In our attrition analyses, we investigated if emotional reactions and mental health at baseline/1st follow-up were associated with the probability of participation in the following survey, i.e., 1st follow-up/2nd follow-up. We cross-tabulated all outcome variables with "participation" in the following survey. Significance tests were obtained from binary logistic regression in which all measures of emotional reactions and mental health were mutually adjusted.

\section{Results}

We found that teachers' fear of infection and transmission as well as their perceived level of stress and burnout and their worries about their ability of managing the working conditions increased from May to November-December 2020. Importantly, in June 2020, we observed a tendency to a stagnation or even a decline in more of these outcomes (Fig. 3A).

The adjusted analyses in the total sample (Table 2) confirm the descriptive findings, with a relatively stable level in the spring and summer followed by a significant increase in all outcomes in the fall with effect estimates indicating a $27-84 \%$ higher prevalence of emotional reactions and poor mental health at 2 nd follow-up. Notably, already at 1 st follow-up, teachers' seemed to worry more about their ability to manage the working conditions, with a change that bordered on statistical significance ( $\mathrm{PR}=1.11$; 95\% CI 0.98-1.27). At the same time (June), fear of transmission to pupils and the level of perceived stress declined.

We also found that teachers, who reported being in a COVID-19 risk group, had a higher level of emotional reactions and poor mental health at most of the measurement points. Notably, in the beginning of the pandemic, we observed a substantial difference between risk groups and non-risk groups (Fig. 3B). The adjusted analyses demonstrated a considerable increase in prevalence of emotional reactions and poor mental health in the risk group, but for fear of infection and fear of transmission to the home the increase was actually lower than expected from the main effects. For the remaining outcomes, the Time $\times$ Risk group interaction term was statistically insignificant (Table 3).

Our attrition analyses showed that the outcomes under study were not systematically associated with drop-out from the study. In total, $47 \%$ of baseline respondents participated in 1st follow-up. Only fear of transmission to family was significantly $(p<0.05)$ associated with a lower probability of subsequent participation ( $45 \%$ versus $50 \%$ ). In total, $70 \%$ of the participants in 1st follow-up participated in 2nd follow-up. A higher probability of participation was borderline statistically significantly $(p<0.1)$ associated with fear of transmission to the home ( $72 \%$ versus $69 \%$ ) and perceived stress $(75 \%$ vs. $69 \%)$. 
80

PANEL A

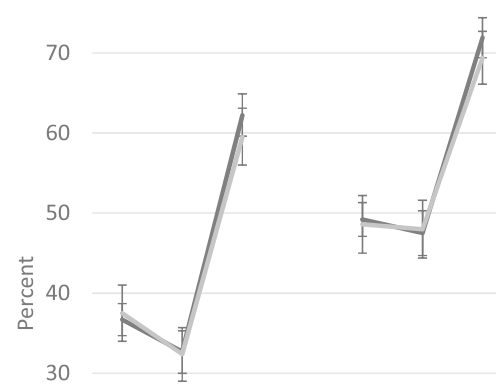

30

20
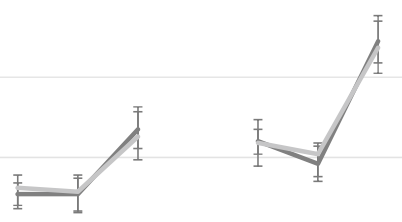

10

0

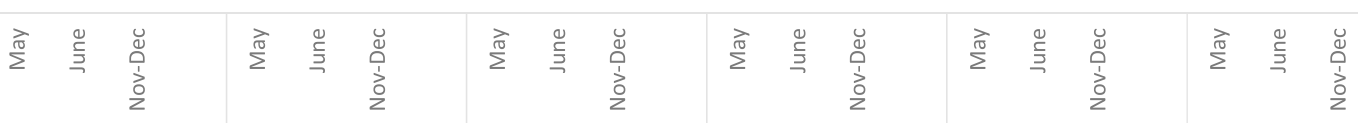

$$
\begin{aligned}
& \begin{array}{l|l|l|l|l}
\text { Fear of infection } & \text { Fear of transmission to } & \text { Fear of transmission to } & \text { Perceived burnout } & \text { Perceived stress Worries regarding }
\end{array} \\
& \begin{array}{|l|l|l|l|l|l}
\text { family } & \text { pupils } & \text { management of }
\end{array} \\
& \text { working } \\
& \text { conditions }
\end{aligned}
$$

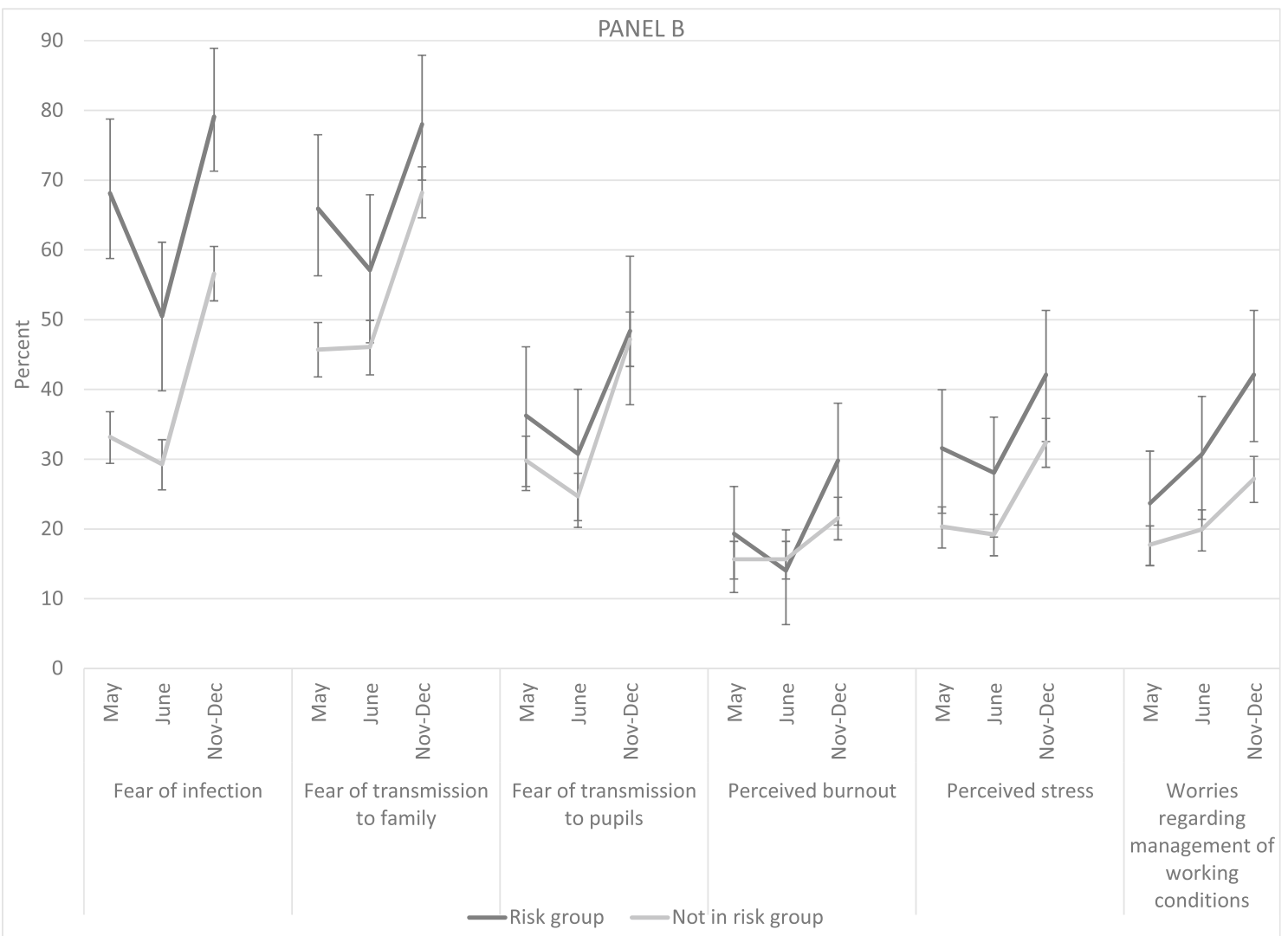

Fig. 3 A Changes in emotional reactions to COVID-19 and mental health among schoolteachers in three phases of the COVID-19 pandemic in Denmark. Separate lines are presented for the total sample at each survey and in the subsample consisting of individuals who participated in all three surveys. B Changes in emotional reactions to
COVID-19 and mental health among schoolteachers in three phases of the COVID-19 pandemic in Denmark. Separate lines are presented for those who reported that they belonged to a risk group and those who did not. Only participants with data from all three surveys are included 
Table 2 Emotional reactions and mental health in June and November-December 2020 (with May as reference) in the total sample, i.e., all participants with non-missing data in one or several surveys are included

\begin{tabular}{|c|c|c|c|c|}
\hline & \multicolumn{2}{|c|}{ June 2020} & \multicolumn{2}{|c|}{ Nov-Dec 2020} \\
\hline & $\mathrm{PR}$ & $95 \% \mathrm{CI}$ & PR & $95 \% \mathrm{CI}$ \\
\hline \multicolumn{5}{|l|}{ Emotional reactions } \\
\hline Fear infection & 0.93 & $0.86-1.02$ & 1.84 & $1.70-1.98$ \\
\hline Fear transmission to home & 0.98 & $0.92-1.05$ & 1.52 & $1.43-1.61$ \\
\hline Fear transmission to pupils & 0.89 & $0.80-0.99$ & 1.71 & $1.56-1.87$ \\
\hline \multicolumn{5}{|l|}{ Mental health } \\
\hline Perceived burnout & 0.87 & $0.75-1.02$ & 1.27 & $1.10-1.47$ \\
\hline Manage working conditions & 1.11 & $0.98-1.27$ & 1.44 & $1.26-1.64$ \\
\hline Perceived stress & 0.86 & $0.76-0.98$ & 1.51 & $1.34-1.69$ \\
\hline
\end{tabular}

Adjusted for gender, age, region, cohabitation, organization of teaching, and pupils' grade

$P R$ prevalence ratios, $C I$ confidence intervals

\section{Discussion}

\section{Main findings}

We found a relatively stable level of the outcome measures from the semi-initial phase of the pandemic (in the wake of the first peak) to the intermediate phase with low infection rates. At this time point, only worries about the ability of managing the working conditions seemed to increase, although emotional reactions to the virus per se (i.e., fear of infection and transmission) seemed to decline somewhat. When facing the second wave of the pandemic, emotional reactions and poor mental health increased with $27-84 \%$ in an adjusted model. Finally, being in a COVID-19 risk group was associated with substantially more prevalent emotional reactions and poor mental health, but contrary to our expectation, they did not increase more than the non-risk group.

\section{Comparison with previous studies}

Whereas most previous studies have mainly been preoccupied with teachers' working conditions during lock-down and the consequent implications of remote teaching (Aperribai et al. 2020; Li et al. 2020b; Lizana and Vega-Fernadez
Table 3 The association between being in a risk group for COVID-19 and changes in emotional reactions and mental health in June and NovemberDecember 2020 (with May as reference)

\begin{tabular}{|c|c|c|c|c|c|c|}
\hline & \multicolumn{2}{|c|}{ May 2020} & \multicolumn{2}{|c|}{ June 2020} & \multicolumn{2}{|c|}{ Nov-Dec 2020} \\
\hline & PR & $95 \% \mathrm{CI}$ & PR & $95 \% \mathrm{CI}$ & PR & $95 \% \mathrm{CI}$ \\
\hline \multicolumn{7}{|l|}{ Fear infection* } \\
\hline Not in risk group & 1.00 & & 0.91 & $0.81-1.02$ & 1.83 & $1.63-2.06$ \\
\hline In risk group & 2.06 & $1.72-2.48$ & 1.59 & $1.26-2.02$ & $2.61 \S^{\downarrow}$ & $2.21-3.11$ \\
\hline \multicolumn{7}{|c|}{ Fear transmission to home* } \\
\hline Not in risk group & 1.00 & & 1.04 & $0.95-1.13$ & 1.58 & $1.44-1.73$ \\
\hline In risk group & 1.49 & $1.26-1.76$ & 1.34 & $1.10-1.63$ & $1.89 \S^{\downarrow}$ & $1.62-2.20$ \\
\hline \multicolumn{7}{|c|}{ Fear transmission to pupils* } \\
\hline Not in risk group & 1.00 & & 0.87 & $0.75-1.01$ & 1.70 & $1.48-1.96$ \\
\hline In risk group & 1.24 & $0.92-1.67$ & 1.12 & $0.80-1.58$ & 1.80 & $1.38-2.35$ \\
\hline \multicolumn{7}{|l|}{ Perceived burnout** } \\
\hline Not in risk group & 1.00 & & 0.89 & $0.72-1.10$ & 1.20 & $1.97-1.47$ \\
\hline In risk group & 1.37 & $0.90-2.07$ & 0.86 & $0.53-1.40$ & 1.78 & $1.25-2.52$ \\
\hline \multicolumn{7}{|l|}{ Perceived stress $* *$} \\
\hline Not in risk group & 1.00 & & 0.96 & $0.81-1.15$ & 1.59 & $1.34-1.89$ \\
\hline In risk group & 1.57 & $1.15-2.14$ & 1.43 & $1.01-2.01$ & 2.10 & $1.58-2.78$ \\
\hline \multicolumn{7}{|c|}{ Manage working conditions** } \\
\hline Not in risk group & 1.00 & & 1.07 & $0.89-1.29$ & 1.45 & $1.18-1.77$ \\
\hline In risk group & 1.41 & $0.98-2.02$ & 1.73 & $1.24-2.42$ & 2.35 & $1.75-3.16$ \\
\hline
\end{tabular}

Participants with non-missing data in all three surveys were included as risk group-status was not available for all participants. Adjusted for gender, age, region, cohabitation, organization of teaching, and pupils' grade

${ }^{\S}$ Significant $(p<0.05)$ interaction between "Time" and "Risk group"; $\downarrow$ Estimate lower than expected from separate main effects; $* n=737$ (participants who had not been physically present at the school were not asked questions about fear of infection and transmission); $* * n=840$ 
2021; Sokal et al. 2020b; Stachteas and Stachteas 2020; Zhou and Yao 2020), the present study addresses emotional reactions to COVID-19 and mental health outcomes among teachers, when schools were partly or mainly open. As has been observed among employees in healthcare and eldercare (Aoyagi et al. 2015; Goulia et al. 2010; Nabe-Nielsen et al. 2020; Seale et al. 2009), fear of infection and transmission of infection and poor mental health outcomes are also present among schoolteachers, and the level fluctuates with the infection/hospitalization rates in the society. A comparison of these fluctuations across nations is complicated by differences in the development of the pandemic as well as the political response, e.g., in terms of school closures (UNESCO 2021). Our findings do, however, resemble those of previous studies of related topics, despite that measurement tools are not exactly similar: A Spanish study reported the prevalence of poor mental health among teachers from pre-school education to university level (depression: 16\%; anxiety: 29\%; stress: 19\%) when reopening educational institutions in September 2020 (Ozamiz-Etxebarria et al. 2020). These figures are similar to our observations from June 2020. One UK report described that the proportion of teachers experiencing high work-related anxiety peaked in the week before initial lockdown and again in the week that school re-opening was announced in June 2020 (Allen et al. 2020). Likewise, we observed a peak immediately before the second school lockdown in December 2020 (Dec 9: 5th to 10th grade; Dec 21: 0th to 4th grade), and also relatively high levels of the outcomes in May 2020 when the youngest pupils were back in school and a reopening for the oldest pupils was announced (Allen et al. 2020).

Based on these findings, knowledge about interventions that can mitigate the potential effects of the pandemic on teachers' mental health are needed. A Chinese study among teachers reported that the most preferred psychological intervention during the pandemic was practice of stress management skills followed by reading psychology education materials, receiving online psychological counseling, and using a telephone hotline (Lizhi et al. 2021). In the context of COVID-19, a mindfulness and cognitive reframing-intervention showed positive effects on resilience and psychological wellbeing of teachers (Zadok-Gurman et al. 2021). Another intervention study partly carried out during the pandemic reported positive effects of a 14-week training program on stress coping ability, burnout, information and communication technology competency and emotional intelligence in the classroom (Pozo-Rico et al. 2020). Thus, it appears that teachers' mental health could be improved through targeted interventions.

When it comes to teachers' risk of infection at the time of the data collection, children did not seem to play a major role in the transmission of SARS-CoV-2 (Macartney et al. 2020; Walger et al. 2020), and being physically present at the schools did not seem to imply a substantially higher risk of infection and possible transmission to the pupils' parents and the teachers' partners compared with remote teaching (Vlachos et al. 2021). Nevertheless, the potential work-related exposure to virus could influence schoolteachers' perception of a safe working environment: In a previous paper, we found that having been exposed to infection or being unaware about exposure to infection were associated with more frequent emotional reactions to the pandemic (Nabe-Nielsen et al. 2021b). In the same vein, perceived risk of COVID-19 infection was associated with a higher level of perceived stress among health and social care professionals (Finell and Vainio 2020). Yet, the subsequent access to vaccination is likely to influence teachers' fear and risk of infection.

Previously, we reported that knowledge about adequate test-behavior and access to personal protective equipment (PPE) were associated with less frequent emotional reactions (Nabe-Nielsen et al. 2021b). Importantly, teachers are less accustomed to the use of PPE compared with, for instance, health professionals (Belingheri et al. 2020). Furthermore, the mere access to PPE may be insufficient: A Chinese study in teachers found that knowledge about proper mask use was necessary to mitigate poor mental health outcomes ( $\mathrm{Li}$ et al. 2021). Additionally, the use of face masks as a PPE in teaching has been questioned due to its negative impact on verbal and non-verbal communication (Spitzer 2020). This finding corresponds with the findings regarding barriers for wearing face masks among healthcare workers (Houghton et al. 2020). From October 2020, schoolteachers in Denmark were allowed to use face shields. Yet, in CLASS data, 48\% of the users reported that it affected their teaching negatively (Nabe-Nielsen et al. 2021a).

Also children can be taught basic hygiene (Walger et al. 2020), but ensuring that children adhere to guidelines regarding hindering spread of infection (e.g., hand washing, disinfection and physical distance) constitutes an additional task that requires time and efforts potentially reallocated from teaching activities (Nabe-Nielsen et al. 2021c). Thus, apart from the perceived threat of exposure to virus, the efforts to protect teachers and pupils from infection and hindering virus outbreaks in schools with subsequent local school closures could be the explanations for the emotional reactions and poor mental health.

\section{Strengths and limitations}

The validity of this study is strengthened by the longitudinal design with data collection during three distinct phases of the COVID-19 outbreak in Denmark. We collected data in collaboration with DLF, which enabled us to conduct a survey with a short notice. Labor unions have high legitimacy and a direct and unhindered access to their members. Thus, partnerships between researchers and labor unions provide 
a unique opportunity for an agile data collection and subsequent dissemination of results.

Data for the current study were collected with a research purpose, which is a strength of our study. Nevertheless, the short time frame for the development of the questionnaires and the continuously changing circumstances did not allow for a thorough validation of the questionnaire. Furthermore, we required that the questionnaire could be filled in within less than $10 \mathrm{~min}$. For this reason, we did not include already existing and comprehensive research-based scales for the assessment of fear of infection (Ahorsu et al. 2020; Bitan et al. 2020) or poor mental health, e.g., depressive symptoms (Bech et al. 2001). This is a limitation of the validity of our study, and therefore we do not argue that our singleitem measures represent different underlying constructs. Actually, in an exploratory factor analysis, we found that the "emotional reaction variables" loaded on one factor and the "mental health variables" loaded on a second factor, and - not surprisingly - each of the two groups of variables is therefore highly interrelated.

Furthermore, although we adjusted for sociodemographic factors, organization of teaching, and the pupils' grades, other factors, such as seasonal fluctuations may influence mental health, although a recent review questions a general seasonal effect on depressive symptoms (Øverland et al. 2019). Furthermore, some of the difference in, for instance perceived stress, could be due to already existing differences between employees with and without chronic conditions (Mutambudzi and Henkens 2020).

The overall response rate in CLASS ranged between $30 \%$ and $59 \%$, and particularly younger age groups were underrepresented, which is a limitation (Nabe-Nielsen et al. 2021b). Yet, our attrition analyses demonstrated that emotional reactions and poor mental health were not systematically associated with drop-out between survey rounds. Furthermore, we found the exact same pattern of changes in the outcome variables (Fig. 3) when including all available data at each time point and when including only the subsample who participated in all three surveys. Participation required internet access via an electronic device (smartphone, laptop or tablet). We do not, however, perceive this as a limitation, as teachers are used to online communication with, for instance, parents, colleagues, and their labor union.

Data from the background population show that fluctuations in "worries about the corona crisis" followed the same pattern as similar indicators in our sample. Yet, the level of anxiety and poor mental health seemed to be more stable in the background population only interrupted by an apparent peak by the end of June 2020 (Coronaminds.dk 2021). We expect that the findings can be generalized to other occupational groups with multiple job-related physical contacts. We suggest that major changes in the organization of the work, i.e., going from remote work to physical presence or vice versa, or being physically present at the workplace with many physical encounters while there are dramatic increases in the infection rates, yield emotional reactions and poorer mental health. Such effects may occur in various occupations, although, we cannot empirically support this claim in the current study. For each occupational group, we suggest that the effect of the pandemic on emotional reactions and mental health may depend on access to (and confidentially with the use of) PPE, adherence to instructions about containment of infection, actual exposure to infection, the perceived threat, training, the amount of additional tasks, social parameters such as support from leaders, and eventually the possibility of vaccination.

\section{Conclusion}

Working in the frontline and meeting multiple demands in this context may yield emotional reactions to COVID-19 and poor mental health. We found that teachers' emotional reactions and mental health changed during three phases of the pandemic with the highest level of fear, worries and perceived burnout and stress when facing the second wave of the pandemic. Teachers, who belong to a COVID-19 risk group, most frequently reported emotional reactions and poor mental health. Continuous awareness of the working conditions of teachers is of importance as their performance is fundamental for the society as a whole. In the post-pandemic period, there may be a need for additional resources allocated to the public schools to catch up with any deficiencies in the acquired skills among pupils and to ensure sufficient staffing for this and other postponed tasks.

Author contributions The collaboration between the University of Copenhagen and Danish Union of Teachers was initiated by KN-N. The aim of this study was proposed by KN-N, KBC, and CJN, and it was discussed and agreed on among all authors. KN-N, NVF, IL, and CJN contributed to the development of the questionnaire, and NVF administered the data collection. KN-N drafted the manuscript. KBC, $\mathrm{NVF}$, IL and CJN critically revised the first version of the manuscript. $\mathrm{KN}-\mathrm{N}$ conducted the statistical analyses with support from KBC. The final version was critically revised and approved by all authors.

Funding This work was supported through the authors' employment and without any external funding.

Availability of data and materials Data are available and can be shared and used for research projects in collaboration with data owners.

\section{Declarations}

Conflict of interest NVF and IL are employed by the Danish Union of Teachers, which works for the promotion of its members' salary level and working conditions. $\mathrm{KN}-\mathrm{N}, \mathrm{KBC}$, and $\mathrm{CJN}$ declare no conflicts of interests. 


\section{References}

Ahorsu DK, Lin CY, Imani V, Saffari M, Griffiths MD, Pakpour AH (2020) The fear of COVID-19 scale: development and initial validation. Int J Ment Health Addict. https://doi.org/10.1007/ s11469-020-00270-8

Allen R, Jerrim J, Sims S (2020) How did the early stages of the COVID-19 pandemic affect teacher wellbeing? Centre for Education Policy and Equalising Opportunities (CEPEO)

Aoyagi Y, Beck CR, Dingwall R, Nguyen-Van-Tam JS (2015) Healthcare workers' willingness to work during an influenza pandemic: a systematic review and meta-analysis. Influenza Other Respir Viruses 9(3):120-130. https://doi.org/10.1111/irv.12310

Aperribai L, Cortabarria L, Aguirre T, Verche E, Borges A (2020) Teacher's physical activity and mental health during lockdown due to the COVID-2019 pandemic. Front Psychol. https://doi.org/ 10.3389/fpsyg.2020.577886

Bech P, Rasmussen NA, Olsen LR, Noerholm V, Abildgaard W (2001) The sensitivity and specificity of the Major Depression Inventory, using the Present State Examination as the index of diagnostic validity. J Affect Disord 66(2-3):159-164

Belingheri M, Paladino ME, Riva MA (2020) COVID-19: health prevention and control in non-healthcare settings. Occup Med (lond) 70(2):82-83. https://doi.org/10.1093/occmed/kqaa048

Bitan DT, Grossman-Giron A, Bloch Y, Mayer Y, Shiffman N, Mendlovic S (2020) Fear of COVID-19 scale: psychometric characteristics, reliability and validity in the Israeli population. Psychiatry Res. https://doi.org/10.1016/j.psychres.2020.113100

Burdorf A, Porru F, Rugulies R (2020) The COVID-19 (Coronavirus) pandemic: consequences for occupational health. Scand J Work Environ Health 46(3):229-230. https://doi.org/10.5271/sjweh. 3893

Chew NWS, Lee GKH, Tan BYQ, Jing M, Goh Y, Ngiam NJH, Yeo LLL, Ahmad A, Ahmed Khan F, Napolean Shanmugam G, Sharma AK, Komalkumar RN, Meenakshi PV, Shah K, Patel B, Chan BPL, Sunny S, Chandra B, Ong JJY, Paliwal PR, Wong LYH, Sagayanathan R, Chen JT, Ying Ng AY, Teoh HL, Tsivgoulis G, Ho CS, Ho RC, Sharma VK (2020) A multinational, multicentre study on the psychological outcomes and associated physical symptoms amongst healthcare workers during COVID19 outbreak. Brain Behav Immun 88:559-565. https://doi.org/10. 1016/j.bbi.2020.04.049

Coronaminds.dk (2021) https://coronaminds.ku.dk/resultater/dansk ernes-mentale-velbefindende-under-coronakrisen/. Retrieved 26 Mar 2021

Finell E, Vainio A (2020) The combined effect of perceived COVID19 infection risk at work and identification with work community with psychosocial wellbeing among finnish social sector and health care workers. Int J Environ Res Public Health. https://doi. org/10.3390/ijerph17207623

Goulia P, Mantas C, Dimitroula D, Mantis D, Hyphantis T (2010) General hospital staff worries, perceived sufficiency of information and associated psychological distress during the $\mathrm{A} / \mathrm{H} 1 \mathrm{~N} 1$ influenza pandemic. BMC Infect Dis 10:322. https://doi.org/10. 1186/1471-2334-10-322

Houghton C, Meskell P, Delaney H, Smalle M, Glenton C, Booth A, Chan XHS, Devane D, Biesty LM (2020) Barriers and facilitators to healthcare workers' adherence with infection prevention and control (IPC) guidelines for respiratory infectious diseases: a rapid qualitative evidence synthesis. Cochrane Database Syst Rev 4(4):Cd013582. https://doi.org/10.1002/14651858.Cd013582

Huang Y, Zhao N (2020) Generalized anxiety disorder, depressive symptoms and sleep quality during COVID-19 outbreak in China: a web-based cross-sectional survey. Psychiatry Res 288:112954. https://doi.org/10.1016/j.psychres.2020.112954
Li D, Lin EZ, Brault MA, Paquette J, Vermund SH, Pollitt KJG (2020a) Reopening Schools after a Novel Coronavirus Surge. In: Paper presented at the The 3rd International Electronic Conference On Environmental Research and Public Health

Li Q, Miao Y, Zeng X, Tarimo CS, Wu C, Wu J (2020b) Prevalence and factors for anxiety during the coronavirus disease 2019 (COVID19) epidemic among the teachers in China. J Affect Disord 277:153-158. https://doi.org/10.1016/j.jad.2020.08.017

Li Q, Tarimo CS, Miao Y, Zeng X, Wu C, Wu J (2021) Effects of mask wearing on anxiety of teachers affected by COVID-19: a large cross-sectional study in China. J Affect Disord 281:574-580. https://doi.org/10.1016/j.jad.2020.11.113

Lizana PA, Vega-Fernadez G (2021) Teacher teleworking during the COVID-19 pandemic: association between work hours, work-family balance and quality of life. Int J Environ Res Public Health. https://doi.org/10.3390/ijerph18147566

Lizana PA, Vega-Fernadez G, Gomez-Bruton A, Leyton B, Lera L (2021) Impact of the COVID-19 pandemic on teacher quality of life: a longitudinal study from before and during the health crisis. Int J Environ Res Public Health. https://doi.org/10.3390/ijerp h18073764

Lizhi X, Peng C, Wanhong Z, Shengmei X, Lingjiang L, Li Z, Xiaoping W, Weihui L (2021) Factors associated with preference of psychological intervention and mental status among Chinese teachers during coronavirus disease 2019: a large cross-sectional survey. Front Psychiatry 12:704010. https://doi.org/10.3389/fpsyt. 2021.704010

Macartney K, Quinn HE, Pillsbury AJ, Koirala A, Deng L, Winkler N, Katelaris AL, O'Sullivan MVN, Dalton C, Wood N (2020) Transmission of SARS-CoV-2 in Australian educational settings: a prospective cohort study. Lancet Child Adolesc Health 4(11):807-816. https://doi.org/10.1016/s2352-4642(20)30251-0

Mutambudzi M, Henkens K (2020) Chronic health conditions and work-related stress in older adults participating in the Dutch workforce. Eur J Ageing 17(4):499-508. https://doi.org/10.1007/ s10433-020-00554-x

Nabe-Nielsen K, Nilsson CJ, Juul-Madsen M, Bredal C, Hansen LOP, Hansen ÅM (2020) COVID-19 risk management at the workplace, fear of infection and fear of transmission of infection among frontline employees. Occup Environ Med. https://doi.org/10.1136/ oemed-2020-106831

Nabe-Nielsen K, Fuglsang NV, Larsen I, Nilsson CJ (2021a) CLASS - Folkeskolelæreres arbejdsmiljø under anden bølge af COVID19-pandemien i Danmark. Københavns Universitet, København

Nabe-Nielsen K, Fuglsang NV, Larsen I, Nilsson CJ (2021b) COVID19 risk management and emotional reactions to COVID-19 among school teachers in Denmark: results from the CLASS study. J Occup Environ Med. https://doi.org/10.1097/JOM.0000000000 002136

Nabe-Nielsen K, Larsen I, Fuglsang NV, Nilsson CJ (2021c) CLASS - Folkeskolelæreres arbejdsmiljø under COVID-19: Udfordringer og mulige løsninger baseret på erfaringer fra juni 2020. Københavns Universitet, København

Naghieh A, Montgomery P, Bonell CP, Thompson M, Aber JL (2015) Organisational interventions for improving wellbeing and reducing work-related stress in teachers. Cochrane Database Syst Rev. https://doi.org/10.1002/14651858.CD010306.pub2

Øverland S, Woicik W, Sikora L, Whittaker K, Heli H, Skjelkvåle FS, Sivertsen B, Colman I (2019) Seasonality and symptoms of depression: a systematic review of the literature. Epidemiol Psychiatr Sci 29:e31. https://doi.org/10.1017/s2045796019000209

Ozamiz-Etxebarria N, Berasategi Santxo N, Idoiaga Mondragon N, Dosil Santamaría M (2020) The psychological state of teachers during the COVID-19 crisis: the challenge of returning to face-toface teaching. Front Psychol 11:620718. https://doi.org/10.3389/ fpsyg.2020.620718 
Pozo-Rico T, Gilar-Corbí R, Izquierdo A, Castejón JL (2020) Teacher training can make a difference: tools to overcome the Impact of COVID-19 on primary schools. an experimental study. Int J Environ Res Public Health. https://doi.org/10.3390/ijerph17228633

Preskorn SH (2020) The 5\% of the population at high risk for severe COVID-19 infection is identifiable and needs to be taken into account when reopening the economy. J Psychiatr Pract 26(3):219-227. https://doi.org/10.1097/pra.0000000000000475

Seale H, Leask J, Po K, MacIntyre CR (2009) "Will they just pack up and leave?"-attitudes and intended behaviour of hospital health care workers during an influenza pandemic. BMC Health Serv Res 9:30. https://doi.org/10.1186/1472-6963-9-30

Sokal L, Trudel LE, Babb J (2020a) Canadian teachers' attitude toward change, efficacy, and burnout during the COVID-19 pandemic. Int J Educ Res Open 1:100016

Sokal LJ, Trudel LGE, Babb JC (2020b) Supporting teachers in times of change: the job demands - resources model and teacher burnout during the COVID-19 pandemic. Int J Cont Edu 3(2):67-74. https://doi.org/10.11114/ijce.v3i2.4931

Song X, Fu W, Liu X, Luo Z, Wang R, Zhou N, Yan S, Lv C (2020) Mental health status of medical staff in emergency departments during the Coronavirus disease 2019 epidemic in China. Brain Behav Immun 88:60-65. https://doi.org/10.1016/j.bbi.2020.06. 002

Spitzer M (2020) Masked education? The benefits and burdens of wearing face masks in schools during the current Corona pandemic. Trends Neurosci Educ 20:100138. https://doi.org/10.1016/j.tine. 2020.100138

Stachteas P, Stachteas C (2020) The psychological impact of the COVID-19 pandemic on secondary school teachers. Psychiatriki 31(4):293-301. https://doi.org/10.22365/jpsych.2020.314.293

Statens Serum Institut (2021) Dagens COVID-19-opgørelser-download filerne her (Daily COVID-19 figures). https://covid19.ssi.dk/ overvagningsdata/download-fil-med-overvaagningdata. Retrieved 31 Jan 2021

Sun N, Wei L, Shi S, Jiao D, Song R, Ma L, Wang H, Wang C, Wang Z, You Y, Liu S, Wang H (2020) A qualitative study on the psychological experience of caregivers of COVID-19 patients. Am J Infect Control 48(6):592-598. https://doi.org/10.1016/j.ajic.2020. 03.018

The Lancet Editorial (2020) The plight of essential workers during the COVID-19 pandemic. Lancet 395(10237):1587. https://doi.org/ 10.1016/s0140-6736(20)31200-9
UNESCO (2021) UNESCO figures show two thirds of an academic year lost on average worldwide due to Covid-19 school closures. https://en.unesco.org/news/unesco-figures-show-two-thirds-acade mic-year-lost-average-worldwide-due-covid-19-school. Retrieved $1 \mathrm{Feb} 2021$

Vindegaard N, Benros ME (2020) COVID-19 pandemic and mental health consequences: systematic review of the current evidence. Brain Behav Immun 89:531-542. https://doi.org/10.1016/j.bbi. 2020.05.048

Viner RM, Russell SJ, Croker H, Packer J, Ward J, Stansfield C, Mytton O, Bonell C, Booy R (2020) School closure and management practices during coronavirus outbreaks including COVID-19: a rapid systematic review. Lancet Child Adolesc Health 4(5):397404. https://doi.org/10.1016/s2352-4642(20)30095-x

Vlachos J, Hertegård E, Svaleryd HB (2021) The effects of school closures on SARS-CoV-2 among parents and teachers. Proc Natl Acad Sci USA. https://doi.org/10.1073/pnas.2020834118

Walger P, Heininger U, Knuf M, Exner M, Popp W, Fischbach T, Trapp S, Hübner J, Herr C, Simon A (2020) Children and adolescents in the CoVid-19 pandemic: schools and daycare centers are to be opened again without restrictions. The protection of teachers, educators, carers and parents and the general hygiene rules do not conflict with this. GMS Hyg Infect Control. https://doi.org/ 10.3205/dgkh000346

Zadok-Gurman T, Jakobovich R, Dvash E, Zafrani K, Rolnik B, Ganz AB, Lev-Ari S (2021) Effect of inquiry-based stress reduction (IBSR) intervention on well-being, resilience and burnout of teachers during the COVID-19 pandemic. Int J Environ Res Public Health. https://doi.org/10.3390/ijerph18073689

Zhou X, Yao B (2020) Social support and acute stress symptoms (ASSs) during the COVID-19 outbreak: deciphering the roles of psychological needs and sense of control. Eur J Psychotraumatol 11(1):1779494. https://doi.org/10.1080/20008198.2020.1779494

Publisher's Note Springer Nature remains neutral with regard to jurisdictional claims in published maps and institutional affiliations. 